\title{
Sex and level of mediator abstractness as variables in mediate association
}

TED CHRISTIANSEN, University of New Mexico, Albuquerque, N.M. 87106

Male and female groups were compared on mixed list chaining paradigms where $B$ terms were concrete or abstract nouns and $A-C$ terms were nonsense syllables. An analysis of the data showed no significant mediation differences for male Ss assigned to concrete as compared to male Ss assigned to abstract mediation treatment; nor for female Ss similarly compared. Insignificant mediation differences also were found when male and female Ss were compared, regardless of the type of mediator employed in the paradigm.

Research studies have consistently shown that pairedassociate (PA) learning is facilitated when concrete words are used in the list (e.g., Bugelski, 1962; Paivio, 1963; Paivio \& Yarmey, 1965). As some researchers have suggested, such findings provide support for the hypothesis that visual imagery is a factor in learning. The manner by which imagery relates to PA learning tasks has been suggested by Miller, Galanter, \& Pribram (1960), who believe visual images serve as mediators by stimulating the recall of associations formed during list learning.

While there is evidence imagery is a factor in PA learning, its role in mediate association has yet to be determined. Research findings in this area are conflicting. For example, Paivio \& Yarmey (1965) compared concrete with abstract nouns in a stimulus equivalence paradigm and found no superiority for either as mediators. Conversely, Christiansen \& Stone (1968) compared these nouns in a chaining paradigm and found concrete nouns superior to abstract as mediators. While the divergent results of the two studies are explainable partly in terms of different paradigms, S's ability to form visual images was controlled in the Christiansen and Stone study. It may be argued, therefore, that control of variables which relate to mediator type will give a more meaningful picture of visual imagery's role in mediation. In line with this viewpoint, and on the basis of some evidence which suggests males are better visualizers than females, ${ }^{1}$ it was decided to arrange paradigms to control for sex as a variable.

\section{METHOD}

Eighty university students ( 40 men and 40 women) enrolled in psychology and special education classes served as Ss. Ss were assigned, according to sex, to one of two lists each of which was subsequently divided in a random fashion to form two male groups (M1 and $\mathrm{M} 2)$ and two female groups ( $\mathrm{F} 1$ and F2) of 20 Ss each.

A three-stage mixed paradigm was designed for each group. The experimental (mediation) condition of the paradigm comprised an A-B, B-C, test A-C arrangement, where B terms were similar sets of either concrete or abstract nouns. The control (nonmediation) condition of the paradigm comprised an $A-B, X-C$, test $A-C$ arrangement, where the $B$ and $X$ terms were different sets of either concrete or abstract nouns. A-C terms were Glaze (1928) nonsense syllables of zero per cent association value. The $B$ and $X$ terms were concrete nouns (e.g., duck, shirt, rabbit) for the Ml and Fl groups and abstract nouns (e.g., income, proof, scheme) for the $\mathrm{M} 2$ and F2 groups. Each stage of the paradigm contained $12 \mathrm{~S}-\mathrm{R}$ pairs (six control and six experimental). Nouns were equated for frequency of usage in materials comprising the ThorndikeLorge (1944) Summary Count and were assigned randomly to the mediation (B) or nonmediation (X) condition in the paradigm. Imagery ratings on all nouns made prior to the experiment showed concrete nouns to be superior in imagery to abstract nouns.

List 1 and List 2 terms were presented on a memory drum using the recall or study-test method. Each S-R pair was presented for study for $2 \mathrm{sec}$. On test trials, the stimulus item alone was shown for $2 \mathrm{sec}$; the S's task was to name the response item. S-R pairs were learned to a criterion of two consecutive perfect trials. Intertrial intervals were $12 \mathrm{sec}$; interstage intervals were $3 \mathrm{~min}$. Lists were presented in three random orders to prevent serial learning.

The A-C test was presented as a recognition task. Sheets of paper containing $12 \mathrm{~A}$ terms, each paired with six $\mathrm{C}$ terms, were distributed to Ss at the termination of List 2 learning. The pairing of $\mathrm{A}$ and $\mathrm{C}$ terms was as follows: The first six $\mathrm{C}$ terms from List 2 were matched with each of the first six A terms from List 1 , while the last six $\mathrm{C}$ terms from List 2 were matched with each of the remaining $\mathrm{A}$ terms. The arrangement of $\mathrm{C}$ terms next to each $\mathrm{A}$ term was randomized to prevent pattern matching. Ss were directed to underline the $\mathrm{C}$ term most closely related to each A term.

\section{RESULTS}

Mean learning rate scores were determined for List 1 (F1-17.0; $\quad$ F2-18.3; $\mathrm{M} 1-16.8 ; \quad \mathrm{M} 2-17.8)$ and List 2 (F1-14.6; F2-16.2; M1-15.2; M2-16.5). An analysis of variance (Lindquist, 1953, pp. 44-46) revealed insignificant learning rate differences for the four groups on each list [List 1: $F(3,76)=.97$, List 2: $F(3,76)=1.4]$. These results indicate the Ss comprising the four groups had comparable learning abilities.

From the data obtained on the A-C test, group means for the mediation and nonmediation conditions were determined. These were: F1 (3.28 and .60), F2 (3.01 and .48), Ml (3.50 and .96), and M2 (3.08 and .60). A 2 by 2 by 2 factorial design analysis of variance (Winer, 1962, pp. 228-258) indicated superiority for the mediation over the nonmediation condition $[F(1,133)=155.4 ; p<.01]$. An insignificant interaction of Sex and Type of Mediator $(F=.92)$ showed no superiority for males over females, and no superiority for concrete over abstract mediators.

\section{DISCUSSION}

A previous study by Christiansen \& Stone (1968) indicated S's ability to form visual images was a factor in mediation, the effect being more pronounced for concrete mediators. Data from a second study 1 suggested that males were better visualizers than females, at least at the 12-year-old level. It was reasoned, therefore, that control of the sex variable experimentally would provide a more sensitive measure of the effectiveness of concrete and abstract nouns as mediators. It was expected concrete nouns would be superior to abstract as mediators. The results of the experiment did not verify these expectations. The data, showing no superiority for concrete over abstract mediators, support the findings of Paivio \& Yarmey (1965). Several explanations may be suggested for these results: S's ability to form visual images was not controlled by $\mathrm{E}$, so it is possible that males and females of similar visual imagery ability were compared. Moreover, college students were used as Ss. The evidence which points to sex differences in visual imagery is based on work done with seventh-grade children. Perhaps such differences lessen in degree or disappear altogether with increasing age of the $S$. 
Table 1

False-Negative Errors as a Function of Coaction, Potential Evaluation, and Session

\begin{tabular}{lllll}
\hline & AP-MC & $\begin{array}{c}\text { Group* } \\
\text { PA-MC }\end{array}$ & AP-PE & PA-PE \\
\hline Session 1 & & & & \\
M & 5.17 & 5.92 & 3.00 & 2.25 \\
SD & 3.21 & 5.35 & 1.65 & 2.30 \\
Session 2 & & & & \\
M & 2.75 & 3.75 & 0.58 & 2.00 \\
SD & 4.16 & 3.47 & 0.79 & 2.13 \\
\hline
\end{tabular}

* $N=12$ in each group

square-root transformation $[(\sqrt{x}+\sqrt{x+1})$ Winer, 1961, p. 220] in parametric analyses, and, as a further safeguard, the data were in some cases subjected to parallel nonparametric analyses.

Under PE (Table 1), Ss produced significantly fewer false-negative errors under coaction than under isolation $(t=3.01, p<.01, p=.008$ by a Fisher-Yates exact test of the direction of differences). Under MC, the presence of coaction left error rates unaffected $(t=0.06)$. The strength of association between coaction and error rate was .53 under PE and .01 under MC, by point-biserial correlation. The difference between the two coefficients yields $z=1.863, p<.10$ two-tailed. The effects of coaction under PE were homogeneous for the three thirds of each vigilance session (Fig. 1), the curves for the AP and PA groups crossing only with the change in the isolation-coaction variable between sessions.

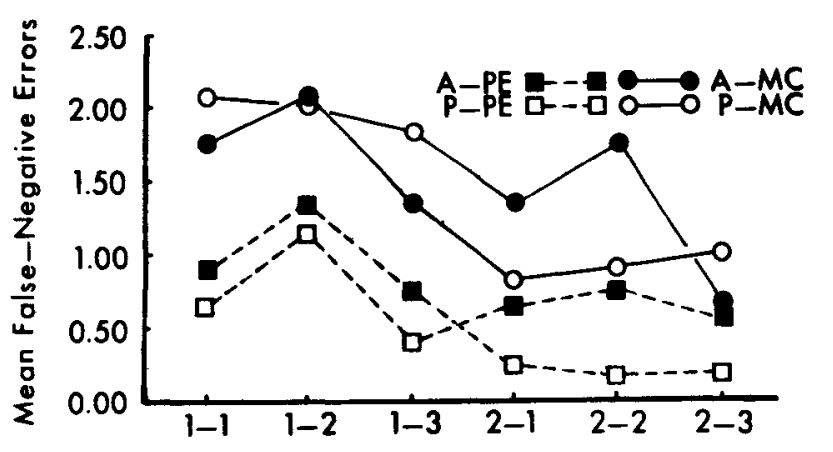

One-Third Session Blocks of Two Vigilance Periods

Fig. 1. False-negative errors as a function of coaction, potential evaluation, and sescion.
The main performance error variable considered here is the number of signals missed. Ss can decrease the number of their false-negative errors, i.e., failing to detect a signal when it was there, by increasing the number of their false-positive errors, that is, by adopting a less stringent criterion for reporting a signal, thus increasing the number of signal reports when the flash was not a signal. If this indeed occurred, improvement in the rate of correct detections would be related to an increase in false detections. An analysis of false-positive errors indicates that PE Ss' improved detection rate under coaction is not attributable to indiscriminate increases in call rates. The correlation between false-negative and false-positive error rates is slightly positive, .39 , which approaches significance at the .05 level.

Mere coaction, i.e., simply the presence of a coactor, was in this study insufficient to improve performance. Performance was improved, however, when the coactor had access to information about the $S$ 's performance, suggesting that potential evaluation is a necessary condition for coaction effects on performance.

\section{REFERENCES}

ANTROBUS, J. S., \& SINGER, J. L. Visual signal detection as a function of sequential variability of simultaneous speech. Joumal of Experimental Psychology, 1964, 68, 603-610.

BERGUM, B. O., \& LEHR, D. J. Vigilance performance as a function of paired monitoring. Journal of Applied Psychology, 1962, 46, 341-343.

BERGUM, B. O., \& LEHR, D. J. Effects of authoritarianism on vigilance performance. Journal of Applied Psychology, 1963, 47, 75-77.

CHASSAN, J. B. On the analysis of simple crossovers with uneaual numbers of replications. Biometrics, 1964, 20, 206-208.

COTTRELL, N. B. Performance in the presence of other human beings: mere presence, audience, and affiliation effects. In E. C. Simmel, R. A. Hoppe, \& G. A. Milton (Eds.), Social faciliation and imitative behavior. Boston: Allyn \& Bacon, 1968. Pp. 91-110.

COTTRELl, N. B., RITTLE, R. H., \& WACK, D. L. Pfesence of an audience and list type (competitional or noncompetitional) as joint determinants of performance in paired-associates learning. Journal of Personality, 1967, 35, 425-434.

COTTRELL, N. B., WACK, D. L., SEKERAK, G. J., \& RITTLE, R. H. The social facilitation of dominant responses by the presence of an audience and the mere presence of others. Journal of Personality \& Social Psychology, in press.

WINER, B. J. Statistical principles in experimental design. New York: McGraw-Hill, 1962.

ZAJONC, R. B. Social facilitation. Science, 1965, 149, 269-274.

ZAJONC, R. B. Social psychology: An experimental approach. Belmont, Calif.: Wadsworth, 1966.

NOTES

1. This research was supported by National Science Foundation Grant GS-1346.

2. The author thanks C. W. Gray for his generous consultative assistance, and R. $O$. Hietala for pervasive assistance with all aspects of the research.

\section{REFERENCES}

BUGELSKI, B. R. Presentation time, total time, and mediation. Journal of Experimental Psychology, 1962, 63, 409-412.

CHRISTIANSEN, T., \& STONE, D. R. Visual imagery and level of mediator abstractness in induced mediation paradigms. Perceptual \& Motor Skills, 1968, 26, 775-779.

GLAZE, J. A. The association value of nonsense syllables. Joumal of Genetic Psychology, 1928, 35, 259-269.

LINDQUIST, E. F. Design and analysis of experiments in psychology and education. Boston: Houghton-Mifflin, 1953.

MILleR, G. A., GAlanTER, E., \& PRIBRAM, K. H. Plans and the structure of behavior. New York: Holt, 1960.

PAIVIO, A. Learning of adjective-noun paired associates as a function of adjective-noun word order and noun abstractness. Canadian Journal of Psy chology, 1963, 17, 370-379.
NOTE

1. Christiansen, T., manuscript submitted for publication. 